\title{
MMT na periferia: quais os limites ao policy space das economias emergentes?
}

\author{
$M M T$ in the periphery: what are the limits to the policy space of emerging
} economies?

\section{Daniela Magalhães Prates*}

\begin{abstract}
Resumo
Esta nota toma como ponto de partida o artigo "As Falhas da Modern Money Theory (MMT)" - de autoria de Ricardo Carneiro e publicado neste número da BKR - para explorar as limitações da MMT na análise do policy space dos países periféricos que se inseriram na globalização financeira no início dos anos 1990, se convertendo em economias emergentes.
\end{abstract}

Palavras-chave: Moderna Teoria Monetária; economias de mercado emergente; autonomia de política econômica; sistema monetário e financeiro internacional.

Classificação JEL: E42, F41, F62.

\begin{abstract}
This note takes as a starting point the article 'The failures of Modern Money Theory' (MMT) authored by Ricardo Carneiro and published in this issue of the BKR- to explore the limitations of MMT in the analysis of the policy space of the peripheral countries that joined financial globalisation in the early 1990s, becoming emerging market economies.
\end{abstract}

Keywords: Modern Monetary Theory; emerging market economies; economic policy autonomy; international monetary and financial system.

JEL Classification: E42, F41, F62.

\footnotetext{
* Economista Sênior da UNCTAD e professora associada (afastada) do IE/UNICAMP. A autora agradece aos pareceristas anônimos da Brazilian Keynesian Review.
} 


\section{Introdução}

Ricardo Carneiro em seu artigo "As falhas da Money Monetary Theory (MMT)" reconhece a relevância da MMT no debate atual sobre políticas econômicas heterodoxas (ou seja, alternativas ao mainstream da economia e establishment político) e debruça-se sobre duas lacunas dessa abordagem. A primeira lacuna é teórica e se refere à concepção do dinheiro, que seria parcial ao enfatizar "seu caráter estatal e de unidade de conta e meio de pagamento, subestimando a sua dimensão privada e seu caráter de reserva de valor". A segunda lacuna refere-se às recomendações de política econômica da MMT que desconsiderariam características específicas do "contexto histórico do capitalismo contemporâneo, financeirizado".

De acordo com o autor, apesar dessas lacunas, do ponto de vista dessas recomendações a MMT teria uma validade "circunscrita ao momento pós-crise e aos países de moeda conversível". Isto porque esse momento foi marcado por uma "preferência absoluta pela liquidez exigindo massivas intervenções dos bancos centrais (...) e "pela "recusa dos governos dos países capitalistas avançados em usar mais decisivamente o gasto público como mecanismo de estímulo à economia" (p.1). Assim, num contexto de "sobreutilização" da política monetária e "subutilização" da política fiscal, teria relevância a recomendação da MMT de se utilizar "mais decisivamente a política fiscal e as formas não canônicas de financiamento do gasto público".

Como menciona o autor, a MMT é objeto de disputas e controvérsias. Por isso, a literatura crítica tanto à abordagem teórica como às recomendações de política econômica da MMT é vasta e envolve não somente autores do mainstream, mas também da heterodoxia, com destaque para expoentes da mesma escola dos próprios "MMTistas", a pós-Keynesiana. Como esses expoentes, Ricardo Carneiro também se baseia nas análises de Keynes (1930 e 1936[1964]) e de autores pós-keynesianos sobretudo Minsky (1986) - na sua avaliação crítica, contribuindo para essa literatura nas duas dimensões acima mencionadas; assim, recomendo sua leitura tanto adeptos como para oponentes da MMT. 
Ao meu ver, embora relevante, a principal contribuição do artigo não reside na crítica à concepção do dinheiro da MMT - cujas "falhas" já foram apontadas por autores pós-keynesianos (ver, por exemplo, Gnos e Rochon, 2002; Rochon e Vernengo, 2003) - , mas na análise dos dois circuitos distintos (do gasto ou déficit público, financiado com emissão monetária estatal, e do gasto privado, financiado como dinheiro bancário) por meio dos balanços uma autoridade monetária-fiscal unificada e dos bancos privados (Diagramas I e II). Mesmo que essa distinção seja na prática uma simplificação analítica, como destaca o autor, essa análise revela as inconsistências teóricas da MMT, especialmente no contexto atual do capitalismo financeirizado e "O caráter inapropriado do programa permanente de política econômica proposto pela MMT para economias financeirizadas e periféricas de alto grau de abertura financeira" (p.20).

Embora o artigo forneça elementos que permitem chegar a essa conclusão, ele não se debruça sobre a inadequação da MMT no caso específico dessas economias, ou seja, nos termos de Prates (2005), dos países periféricos que se inseriram na globalização financeira, se convertendo em economias emergentes. Não se debruça, porque não é seu objetivo. Mas algumas menções importantes a esse caso específico são feitas. Por exemplo, o autor ressalta o tratamento insuficiente (e ao meu ver inadequado) ao setor externo em Wray (2015) - que se concentra na balança comercial e de transações correntes, ou seja, nos fluxos líquidos de capitais -, enquanto são os fluxos brutos de capitais o aspecto central da trajetória dos balanços de pagamentos contemporâneos (como mostram Borio e Disyatat, 2015); e também que "a operação cambial de conversão da moeda doméstica em divisas, uma forma de esterilização (...) tem impactos cruciais, para moedas periféricas implicando ceteris paribus, desvalorizações da moeda local. A desvalorização da moeda doméstica impõe para os agentes endividados em moeda reserva o currency mismatch, implicando desequilíbrios de balanço de graus variados. Ao mesmo tempo, implica efeitos no nível de preços domésticos por conta da fixação de vários preços relevantes em moeda reserva, o denominado passtrough" (p. 14).

A literatura crítica à MMT também já está repleta de artigos de economistas heterodoxos sobre a sua inadequação para os países periféricos em geral e as 
economias emergentes em particular (ver, por exemplo, Vergnhanini e Conti, 2017; Bonizzi, Kaltenbrunner e Michell, 2019; Epstein, 2019; Vernengo e Caldentey, 2019, e; Prates, 2020). A próxima seção procura contribuir para o melhor entendimento dessa inadequação a partir do resumo da abordagem da MMT sobre o policy space (ou seja, a autonomia de política econômica) nesses países e uma breve apreciação crítica com base em Prates (2020).

Antes de iniciar, contudo, gostaria de compartilhar uma divergência em relação à análise do autor, que se refere à afirmação de que MMT teria uma validade "circunscrita ao momento pós-crise e aos países de moeda conversível". Ao meu ver, sua validade não é a mesma para os países de moeda conversível, ou seja, que emitem moedas aceitas em âmbito internacional (classificados como centrais, desenvolvidos ou avançadas). Em primeiro lugar, os Estados Unidos, país emissor da divisa-chave do sistema monetário internacional contemporâneo, têm o maior policy-space e, assim, a validade (e também viabilidade) das recomendações de política da MMT é maior para esse país. Em segundo lugar, o policy-space e, consequentemente, a validade e viabilidade dessas recomendações, não são os mesmos para os demais países que emitem moeda aceita internacionalmente, mas também depende do seu grau de soberania monetária. A área do euro tem um menor grau de soberania monetária que seus pares e, como mostrou a crise do euro, um menor policy space para adotar o programa de política econômica da MMT. A relação entre policy space e soberania monetária, que considero uma importante contribuição da MMT, também é abordada a seguir.

\section{Policy space das economias emergentes segundo a MMT}

Como destaca Lavoie (2013), as controvérsias em torno da MMT mesmo no campo heterodoxo decorrem, em parte, dos "paradoxal claims" e "problems of terminology" dessa abordagem. $\mathrm{Na}$ análise do policy space das economias emergentes, além desses dois aspectos, nos deparamos com uma dificuldade adicional, qual seja, a existência de distintas versões entre os diferentes autores e mesmo entre o mesmo autor. Neste último caso, o problema, em si, não são mudanças de posições, que podem ocorrer ao longo da evolução das reflexões de 
um autor, como observado, inclusive, nas obras de grandes pensadores. A dificuldade no caso da MMT é a não explicitação dessas mudanças, ou seja, a não referência à diferente abordagem em relação seja a outros autores, seja a textos anteriores de um mesmo autor. A seguir, apresento sumariamente as três versões com as quais me deparei nas minhas leituras (ver quadros abaixo) e mostro como todas chegam à mesma conclusão, com a qual eu discordo. Em seguida, resumo minha crítica à abordagem da MMT sobre o policy space das economias emergentes.

Na visão da MMT, o policy space de um país - para atingir objetivos econômicos e sociais, como pleno emprego, redução da desigualdade e crescimento econômico com base na política fiscal mediante o programa de política econômica resumido por Carneiro - depende de duas variáveis: a soberania monetária e o regime cambial.

Embora o conceito de soberania monetária seja central na MMT (Bonizzi et al., 2019), ele não é o mesmo nas três versões ${ }^{1}$. Os denominadores comuns são: (i) o conceito de soberania, que se refere à soberania política, ou seja, o estado é o soberano, tendo o poder absoluto de governar seu território sem interferências externas; (ii) a natureza do dinheiro: o dinheiro é a unidade de conta definida pelo estado, que impõe as obrigações governamentais (impostos, taxas, etc) nessa unidade de conta; somente em seguida, o estado é capaz de emitir a moeda estatal fiduciária, que é denominada nessa mesma unidade de conta; (iii) a aceitabilidade do dinheiro: "taxes drive money", ou seja, o dinheiro é aceito porque é necessário para pagar as obrigações estatais²; (iv) o governo soberano, enquanto "monopoly issuer", não pode se tornar insolventes na sua própria moeda, ou seja, não haveria limite para seu endividamento denominado no dinheiro doméstico. ${ }^{3}$

Na Versão 1 (apresentada no "primer" de Randall Wray - ver figura 1), essas quatro condições são necessárias e suficientes para que um país tenha soberania

\footnotetext{
${ }^{1}$ Sobre os diferentes conceitos de soberania e soberania monetária na literatura, ver Prates (2021).

${ }^{2}$ Segundo Wray (2015, p. 15), "all the sovereign government needs to do is to promise 'This note will be accepted in tax payment' in order to ensure general acceptability domestically and even abroad". Contudo, o autor não explica como a aceitação da moeda estatal no pagamento de impostos garantirá sua aceitação em âmbito internacional.

${ }^{3}$ Vale mencionar que a hipótese de consolidação do Banco Central e do Tesouro não é necessária para essa condição seja verificada (Prates, 2020).
} 
monetária ${ }^{4}$. Assim, países com sistemas monetários dolarizados ou com moedas conversíveis em metais preciosos ou moedas estrangeiras (currency boards) e uniões monetárias (como a área do euro) não teriam soberania monetária. Consequentemente, esses governos estariam sujeitos a restrições orçamentárias e risco de solvência. Wray (2015) afirma que os benefícios derivados da soberania monetária se aplicariam tanto a países desenvolvidos como em desenvolvimento, mas reconhece que "many developing countries will not find foreign demand for their domestic currency liabilities" (p. 124). Assim, caso esses países incorram em déficit em conta corrente, eles precisarão emitir dívidas denominadas nas "highly desired currencies", ou seja, em dólar americano, sobretudo, e nas demais moedas dos países desenvolvidos.

Em seguida, Wray (2015) analisa as estratégias de política que as nações em desenvolvimento poderiam adotar para aumentar seu policy space. Em primeiro lugar, os governos não deveriam emitir dívida denominada moeda estrangeira, pois estes resultariam em risco de solvência e, assim, imporiam restrições à política monetária doméstica. Em segundo lugar, o grau de policy space dependeria do regime cambial adotado. Wray recorre explicitamente ao conceito de "trilemma" do mainstream da economia para defender que o regime de câmbio flutuante garantiria o maior grau de policy space, de acordo com o qual um governo pode escolher duas entre as três opções seguintes: independência de política monetária, taxa de câmbio fixa e livre mobilidade de capitais.

Assim, para Wray (2015), o regime de câmbio flutuante com livre mobilidade de capitais garantiria o maior grau de autonomia de política econômica para um país em desenvolvimento com soberania monetária. Mas, essa opção de política econômica não seria necessária para garantir o ajustamento do balanço de pagamentos, como na versão do mainstream ${ }^{5}$. Isto porque, seria:

[...] misleading to call a current account deficit an 'imbalance'; by definition it is balanced by the capital account flows. In that sense, it 'takes two to tango': a nation cannot run a current account deficit unless someone wants to hold its IOUs. We can view the current account as resulting from the

\footnotetext{
${ }^{4}$ Para maiores detalhes sobre essa versão, ver Prates (2020).

${ }^{5}$ Ver a formulação original de Mundell (1963).
} 
rest-of-the-world desire to accumulate net savings in the form of claims on the country (p. 130-131).

Afirmações semelhantes são encontradas em textos de vários outros MMTers (ver Bonizzi et al., 2019), que também consideram que a flutuação cambial e o relaxamento dos controles de capitais permitiriam a um país ter mais "benefícios" (importações) do que "custos" (exportações) (Wray, 2014).

Na Versão 2 (ver figura 2), a adoção do regime de câmbio flutuante seria uma pré-condição adicional para um país ter soberania monetária. Todos demais regimes cambiais (inclusive "fixed exchange rate" e "managed exchange rate", respectivamente, regimes de câmbio fixo e administrado) tornariam o país não soberano monetariamente. E somente um país com soberania monetária teria policy space desde que não emita dívida denominada em moeda estrangeira.

Na Versão 3 (ver figura 3), o grau de policy space da Versão 1 é substituído por grau de soberania monetária (ou seja, os dois termos também são sinônimos como na versão 2), sendo que o maior grau de soberania monetária corresponderia à adoção do regime de câmbio flutuante, também com a condição de não emissão de dívida soberana denominada em moeda estrangeira ${ }^{6}$.

Mas, nas três versões, um regime de câmbio flutuante corresponde ao conceito-padrão da literatura econômica, tanto no âmbito do mainstream como da heterodoxia, qual seja, flutuação livre ou pura, sem intervenção do banco central no mercado de câmbio? Aqui, mais uma vez, os autores da MMT não são sempre claros. No entendimento da maioria dos autores, Wray (2015) e textos anteriores da MMT se referem ao conceito-padrão (por exemplo, Lavoie, 2013 e 2014; Bonizzi et al, 2019; Prates, 2020). A referência ao "trilemma" por Wray (2015) sanciona essa interpretação uma vez que nesse arcabouço há somente dois regimes cambiais: fixo e flutuação pura. Contudo, Mitchell et al. (2019, p.14) parecem identificar o regime de câmbio flutuante também com flutuação suja ao afirmarem que "although after 1971 most currencies float freely against each other, occasionally "central banks would conduct

${ }^{6}$ Esta é a interpretação de Lavoie (2013) e Bonizzi er al. (2019) para o conceito de soberania monetária da MMT. 
What became known as a 'managed' float where they tried to limit the amplitude of movements the free float would generate" (grifos nossos).

Figura 1 - Policy space, soberania monetária e regimes cambiais: versão 1

\begin{tabular}{|c|c|c|c|}
\hline Moeda não-soberana & \multicolumn{3}{|c|}{ Moeda soberana } \\
\hline $\begin{array}{c}\text { Moeda estrangeira, moeda } \\
\frac{\text { conversível e uniões }}{\text { monetárias* }}\end{array}$ & $\underline{\text { Taxa de câmbio fixa }}$ & $\frac{\text { Taxa de câmbio }}{\underline{\text { administrada }}}$ & $\frac{\text { Taxa de câmbio }}{\underline{\text { flutuante }}}$ \\
\hline \multicolumn{4}{|c|}{ Grau de policy Space } \\
\hline Menor & & & Maior \\
\hline- & & & + \\
\hline
\end{tabular}

Fonte: Elaboração própria com base em Wray (2015)

* Países membros de uniões monetárias, como a área do euro.

Figura 2 - Policy space, soberania monetária e regimes cambiais: versão 2

\begin{tabular}{|l|l|l|l|}
\hline \multicolumn{2}{|c|}{ Moeda não-soberana } & Moeda soberana \\
\hline $\begin{array}{c}\text { Moeda estrangeira, } \\
\text { moeda conversível e }\end{array}$ & Taxa de câmbio fixa & $\frac{\text { Taxa de câmbio }}{\text { uniões monetárias * }}$ & $\underline{\text { Taxa de câmbio }}$ \\
& & $\underline{\text { flutuante }}$ \\
\hline
\end{tabular}

Fonte: Elaboração própria com base em Wray $(1998,2002)$ e Tcherneva (2006)

* Países membros de uniões monetárias, como a área do euro.

Figura 3 - Policy space, soberania monetária e regimes cambiais: versão 3

\begin{tabular}{|c|c|c|c|}
\hline $\begin{array}{l}\text { Moeda estrangeira, moeda } \\
\frac{\text { conversível e uniões }}{\text { monetárias * }}\end{array}$ & Taxa de câmbio fixa & $\frac{\text { Taxa de câmbio }}{\underline{\text { administrada }}}$ & $\frac{\text { Taxa de câmbio }}{\underline{\text { flutuante }}}$ \\
\hline \multicolumn{4}{|c|}{ Grau de soberania monetária } \\
\hline Menor & & & Maior \\
\hline - & & $\longrightarrow$ & + \\
\hline
\end{tabular}

Fonte: Elaboração própria com base em Tcherneva (2016).

* Pá́ses membros de uniões monetárias, como a área do euro. 
Qual o "resumo da ópera" sobre as três versões da MMT no que diz respeito ao policy space nos países em desenvolvimento? Todas essas versões nos levam à mesma conclusão: o regime de câmbio flutuante (livre ou com intervenções ocasionais) com livre mobilidade de capitais e não endividamento soberano em moeda estrangeira resulta no maior policy space. Adicionalmente, essa estratégia não teria como objetivo ajustar o balanço de pagamentos pois seria "misleading" (ou seja, enganoso) chamar um déficit em conta corrente um desequilíbrio pois, por definição, ele seria sempre equilibrado pelos "capital account flows", ou seja, pelos fluxos líquidos de capitais.

Na perspectiva aqui adotada, essa conclusão da MMT sobre o policy space dos países em desenvolvimento - que se aplicaria, na realidade, às economias emergentes, que possuem alto grau de abertura financeira (ou seja, mobilidade de capitais) - revela uma análise "misleading" de dois aspectos. $\bigcirc$ primeiro, por ser mais geral, refere-se à dinâmica macroeconômica das economias abertas (inclusive dos países desenvolvidos). A igualdade entre os saldos nas transações correntes e na conta capital e financeira (com sinal inverso) é uma identidade macroeconômica que sempre se verifica ex-post (como a igualdade entre poupança e investimento). Nas palavras de Borio e Disyatat (2015, p.7), "current accounts do not unveil financing patterns". Como apontado por Carneiro, o aspecto central da trajetória dos balanços de pagamentos contemporâneos são os fluxos brutos de capitais.

O segundo aspecto diz respeito à forma de inserção das economias emergentes no sistema monetário e financeiro internacional (SMFI) e na divisão internacional do trabalho do capitalismo financeirizado. Como detalha Prates (2020) com base numa abordagem pós-Keynesiana estruturalista, com exceção dos Estados Unidos, emissor da divisa-chave deste sistema - o dólar flexível, financeiro e fiduciário -, todos os países deparam-se com um "dilemma” (Rey, 2013), e não com um "trilemma”, ou seja, o regime de câmbio flutuante não garante autonomia de política monetária com livre mobilidade de capitais. Contudo, no caso das economias emergentes, o grau de autonomia é ainda menor, ou seja, existe uma assimetria macroeconômica que decorre das assimetrias do SMFI contemporâneo. A assimetria monetária - que é consequência da hierarquia de moedas inerente a todos 
SMFI ancorados numa divisa-chave $(1930,1944)$ - se tornou ainda mais perversa para os países periféricos cujas moedas situam-se no piso da hierarquia (por não serem aceitas em âmbito internacional) no contexto da globalização financeira. Neste contexto, as economias emergentes deparam-se com uma assimetria financeira que possui duas dimensões: por um lado, os fluxos brutos de capitais para essas economias, que são business cycle takers, (Ocampo, 2001) são determinados por fatores externos gerados no "centro"; por outro lado, sua inserção nesses fluxos, embora crescente desde os anos 1990, ainda é marginal. A interação dessas duas dimensões resulta numa alta vulnerabilidade aos boom-bust dos ciclos de liquidez internacional. Essas mesmas assimetrias explicam a maior volatilidade cambial nessas economias e a adoção, de facto, dos regimes de flutuação suja após as crises financeiras dos anos 1990. Nesses regimes, as intervenções dos bancos centrais são permanentes, não ocasionais, em função de vários efeitos adversos dessa volatilidade sobre a inflação, a situação financeira dos agentes endividados em moeda estrangeira, entre outros ${ }^{7}$.

No contexto pós-Bretton Woods, as assimetrias monetária e financeira sobrepuseram às assimetrias tecnológica e produtiva destacadas pela literatura estruturalista (Prebish, 1949; Ocampo, 2001;), que explicam, em última instância, a restrição externa estrutural enfrentada pelos países periféricos que persiste na atual divisão internacional de trabalho (Porcile, 2021) e os tornam especialmente vulneráveis ao choques exógenos e dependentes de financiamento externo - ou seja, o endividamento em moeda estrangeira, na maioria dos casos, não é uma escolha, a única alternativa disponível de financiamento. No caso das economias emergentes, a crescente participação de não-residentes nos mercados domésticos de títulos públicos soberanos tem substituído do endividamento mediante emissão de títulos no mercado financeiro internacional denominado em moedas centrais, mas essa substituição não garante maior "policy space", como supõe a MMT, pois em momentos de alta preferência pela liquidez os investidores globais reagem em

\footnotetext{
${ }^{7}$ Para maiores detalhes sobre as assimetrias monetária e financeira e suas implicações para a dinâmica cambial e a autonomia de política econômica das economias emergentes, ver, respectivamente: Andrade e Prates (2013) e Paula et al. (2017).
} 
"manada", liquidando em massa suas posições nesses mercados (como observado no ápice da crise do Covid-19 em março de 2020).

Assim, se consideramos essas quatro assimetrias - que decorrem da natureza centro-periferia do sistema econômico mundial - chegamos a conclusões muito diferentes da MMT. Prates (2020) propõe que é possível identificar diferentes grupos de países no que se refere ao grau de policy space a partir da interação de dois fatores: a posição na hierarquia de moedas e o grau de soberania monetária ${ }^{8}$. Em cada grupo, o policy space dependerá do grau de restrição externa e do regime macroeconômico.

\section{Referências}

Andrade, R. and D.M. Prates (2013), 'Exchange rate dynamics in a peripheral monetary economy', Journal of Post Keynesian Economics, 35 (3), p. 399-416. doi: 10.2753/PKE0160-3477350304

Bonizzi, B.; A. Kaltenbrunner. A.; J. Michell. (2019), Monetary sovereignty is a spectrum: Modern monetary theory and developing countries. Real-world economics review, p. 89, 46-61.

Borio C. and P. Disyatat (2015), 'Capital flows and the current account: Taking financing (more) seriously', BIS Working Paper 525.

Epstein, G. (2019), The institutional, empirical and policy limits of 'modern money theory, PERI Working Papers Series n.481.

Gnos, C. and L. P. Rochon (2002), 'Money creation and the state: A critical assessment of chartalism', International Journal of Political Economy, 32 (3), p.41-57, doi: 10.1080/08911916.2002.11042881.

Keynes, J.M. (1930), The treatise on money. Cambridge: Cambridge University Press.

Keynes, J.M. (1936 [1964]), The general theory of employment, interest, and money, reprinted 1964, London: Macmillan \& Co Ltd.

\footnotetext{
${ }^{8}$ A autora também propõe um conceito de soberania monetária alternativo ao conceito de Wray (2015).
} 
Lavoie, M. (2013), 'The monetary and fiscal nexus of neo-chartalism: a friendly critique', Journal of Economic Issues, 47(1), p.1-32, doi: 10.2753/JEI00213624470101.

Lavoie, M. (2014), Foundations of post-keynesian economic analysis, Aldershot: Edward Elgar

Minsky, H. (1986), Stabilizing an unstable economy, New Haven: Yale University Press.

Mitchell, W; Wray, R. L.; Watts, M. (2019), Macroeconomics, UK: Red Globe Press.

Mundell, R. A. (1963), 'Capital mobility and stabilization policy under fixed and flexible exchange rates', The Canadian Journal of Economics and Political Science, 29(4), p.475-485.

Ocampo, J.A. (2001), International asymmetries and the design of the international financial system. CEPAL Serie Temas de Coyuntura n. 15. Santiago de Chile: CEPAL.

Paula, L. F. R., B. Fritz, B. and D. M. Prates (2017), 'Keynes at the periphery: Currency hierarchy and challenges for economic policy in emerging economies', Journal of Post Keynesian Economics, 40(2), p.183-202, doi: 10.1080/01603477.2016.1252267.

Porcile, G. (2021), "Latin-American structuralism and neo-structuralism." In: L. Alcorta, N. Foster-McGregor, B. Verspagen, A. Szirmai (editors), New perspectives on structural change: Causes and consequences of structural change in the global economy, part 1, ch.3. Oxford: Oxford University Press.

Prates, D. M. (2005), As assimetrias do sistema monetário e financeiro internacional. Revista de Economia Contemporânea, mai/ago, 9(2), p.263-288.

Prates, D. (2020), Beyond modern money theory: A Post-Keynesian approach to the currency hierarchy, monetary sovereignty, and policy space. Review of Keynesian Economics, 8(4), p.494-511, doi:10.4337/roke.2020.04.03

Prates, D. (2021), Monetary sovereignty in the post keynesian perspective: in the search of a concept, in Bonizzi, B., Kaltenbrunner, A. e Ramos, R.A. (eds). 
Emerging Economies and the Global Financial System Post-Keynesian Analysis, London: Routledge, cap. 16.

Prebisch, R. (1949), The economic development of Latin America and its principal problems, New York, United Nations Department of Economic Affairs.

Rey, H. (2013), 'Dilemma not trilemma: The global financial cycle and monetary policy independence', paper presented at the Jackson Hole Symposium.

Rochon, L.P. and M. Vernengo (2003), 'State money and the real world: Or chartalism and its discontents', Journal of Post Keynesian Economics, 26(1), p.57-68, doi: 10.1080/01603477.2003.11051383

Tcherneva, P. R. (2006), 'Chartalism and the tax-driven approach', In.: Arestis, P. and Sawyer, M. A Handbook of alternative monetary economics, Cheltenham, Edward Elgar, p. 69-86.

Therneva, P.R. (2016), "Money, power, and monetary regimes." Levy Economics Institute, Working Paper (861).

Vergnhanini, R. and B. M. De Conti (2017), 'Modern Money Theory: a criticism from the periphery', Brazilian Keynesian Review, 3(2), p.16-31, doi: 10.33834/bkr.v3i2.115

Vernengo, M. and E.P. Caldentey (2019), 'Modern Money Theory (MMT) in the tropics: functional finance in developing countries,' Working Paper 459, PERI Working Paper Series.

Wray, R. (1998), Understanding modern money: The key for full employment and price stability, Cheltenham and Northampton: Edward Elgar.

Wray, R. (2002), 'State money', International Journal of Political Economy, 32(3), p.23-40, doi: 10.1080/08911916.2002.11042877

Wray, R. (2015), Modern money theory: A primer on macroeconomics for sovereign monetary systems, 2nd edition, New York: Palgrave Macmillan. 